\title{
Hemodiyaliz Hastalarında Sigara Kullanımı, Nikotin Bağımlılık Durumu ve İlişkili Faktörler
}

\section{Smoking, Nicotine Dependence And Related Factors In Hemodialysis Patients}

\author{
Zeynep Kendi Çelebi ${ }^{1 *}$, Didem Turgut ${ }^{1}$ \\ ${ }^{1}$ Başkent Üniversitesi Tıp Fakültesi Nefroloji Bilim Dalı, Ankara, Türkiye \\ e-mail: zeynepkendi@yahoo.com,dr.didem@gmail.com \\ ORCID: 0000-0003-3279-9796 \\ ORCID: 0000-0001-7474-5927 \\ *Sorumlu Yazar / Corresponding Author: Sorumlu Yazar: Zeynep Kendi Çelebi ${ }^{1}$ \\ Gönderim Tarihi / Received: 09.12.2019 \\ Kabul Tarihi / Accepted: 07.05.2020 \\ DOI: $10.34087 /$ cbusbed.657354
}

\begin{abstract}
Öz
Giriş ve Amaç: Sigara kullanımı tüm dünyada sıklığı yüksek olan önemli bir halk sağlığı problemidir. Özellikli olan hemodiyaliz hasta grubunda da bu sorun önemli oranda devam etmektedir. Ancak hemodiyaliz hastalarında sigara içenlerde hastaların bağımlılık düzeyleri ile bu durumu etkileyen faktörler farklılık gösterebilmektedir.

Gereç ve Yöntemler: Programlı hemodiyaliz ile takip edilen hastalarda sigara kullanımı, eşlik eden komorbid durumlar ve Fagerstörm nikotin bağımlılık testi ile nikotin bağımlılığı ölçüldü. 36 aylık mortalite oranları değerlendirildi.

Bulgular: 239 hastanın değerlendirildiği çalışmada 43 (\%18) hastanın aktif sigara içicisi olduğu görüldü. Erkeklerin, evli olanların ve fazla sigara içenlerin nikotin bağımlılık skorları yüksek bulundu. Aktif sigara kullanan hastalarla diğer hastalar arsında 36. ay mortalite arasında fark bulunmadı $(\mathrm{p}=0,054)$.

Sonuç: Yüksek kardiyak riski olan hemodiyaliz hastalarında sigara kullanımı yeni riskler oluşturmaktadır. Bu hasta grubunda seanslarda sağlanacak eğitim ve sosyal destek programları ile daha kolay sigara bırakma sağlanabileceği akılda tutulmalıdir.
\end{abstract}

Anahtar Kelimeler: Hemodiyaliz, nikotin bağımlılığı, sigara içme

\begin{abstract}
Objective: Cigarette smoking is an important public health problem with a high prevalence all over the world. It is also prominent for hemodialysis patients. But the effect of smoking in the dialysis population or nicotine dependence level is less well studied.

Materials and Methods: Adults treated with long-term hemodialysis were analyzed in respect to smoking habits, associated comorbidities and physical addiction level to nicotine with Fagerström Test for Nicotine Dependence (FTND).

Results: We analyzed 239 hemodialysis patients. 43 (18\%) patients were active smoker. Males, married ones and heavy smokers were with high nicotine dependence. There was no statistically significant difference for $36^{\text {th }}$ month mortality between current smokers and others $(\mathrm{p}=0,054)$.

Conclusion: Cigarette smoking accounts for serious new problems in hemodialysis patients who have already high cardiovascular risks. In this patient group, it would be easy to control this modifiable risk factor with education and social support during dialysis sessions.
\end{abstract}

Keywords: Hemodialysis, nicotine dependence, smoking

\section{Giriș}

Sigara kullanımının insan sağlığı üzerine olan etkileri tüm dünyaca bilinmektedir. Dünya Sağlık Örgütü’nün ülkemizde tütün ürünlerinin kullanımı için bildirdiği prevalans erkeklerde \%39,5, kadınlarda \%12,4’tür. Sigara kullanımı, en önemli önlenebilir ölüm 
nedenlerinden biridir [1]. Sigara içen insanlarda total mortalite içmeyen kişilere göre üç kat artmaktadır ve mortalitedeki artış, kanser, solunum sistemi hastalıkları ve kardiyovasküler hastalıklar gibi direkt sigara ilişkili hastalıklardır [2]. Hemodiyaliz hastalarında sigaranın etkileri tam olarak bilinmemektedir. Dünyada hemodiayliz hastalarında bildirilen mortalite oranları $\% 15-20$ arasındadır ve en sık kardiyak nedenlerle ilişkilidir [3]. Ülkemizde ise Türk Nefroloji Derneği kayıtlarına bakıldığında hemodiyaliz hastalarında mortalitenin \%10 civarında olduğu görülmektedir [4]. Kardiyak mortalitenin çok yüksek olduğu bu hasta grubunda sigara içiminin ek zararları, yeni yan etkileri net değildir.

Sigara içen kişilerin önemli bir bölümü, sigarayı bırakmak istedikleri halde, nikotin bağımlılığı nedeni ile sigarayı bırakamamaktadırlar. Bırakmak isteyenlerde bağımlılık düzeyinin tespiti tedavinin seçimi ve bırakma başarısı açısından önem taşımaktadır. Dünyada hemodiyaliz hastalarında sigara kullanım sıklığı \%6-13 arasındadır [5]. Bu grup hastalarda sigara bağımlılığının seviyesi hakkında yapılmış çalışma bulunmamaktadır.

$\mathrm{Bu}$ çalışmanın amacı, mortalite oranı yüksek olan bu hasta grubunda sigara kullanım durumlarını, sigara kullanmaya devam eden hastaların bağımlılık düzeyleri ile bu durumu etkileyen faktörlerin değerlendirilmesidir.

\section{Materyal ve Metot}

Çalışmaya 2016 yılında Amasya ili ve ilçelerinde düzenli hemodiyaliz tedavisi alan ve çalışmaya katılmayı kabul eden hastalar alındı. Hastaların yaş, cinsiyet, öğrenim durumu, medeni hali, komorbiditeleri, primer hastalıkları, operasyon öyküsü değerlendirildi. Hastaların eşlik eden komorbid durumları Charlson komorbidite indeksi ile hesaplandı [6]. Hastalara sigara içip içmeme durumları, bırakanların ne zaman bıraktığı, sigara içmeye devam eden ya da sigarayı bırakmış hastaların maruz kaldığı sigara miktarı (paket/yıl), hemodiyaliz süresi ile sigara bırakma zamanı sorgulandı. Hastalara Türkçe geçerliliği gösterilmiş olan Fagerstörm nikotin bağımlılık testi (FBNT, 0-2: Çok az bağımlılık, 3-4: Az bağımlılık, 5: Orta derecede bağımlı, 6-7: Yüksek bağımlılık, 8-10: Çok yüksek bağımlılık) uygulanarak bağımlılık düzeyleri belirlendi [7]. FNBT hastalara aynı kişi tarafından uygulandı ve skorlar kaydedildi. Hastaların diyaliz yeterliliği, hastanın diyaliz tedavisi ile ilgili soruların bulunduğu, hemoglobin, kalsiyum fosfor, parathormon, ferritin, albümin, kuru ağırlık, kan basıncı, kt/v ve ilaç kullanımı değerlendirildi [8]. Hastalar 36 ay sonra mortalite açısından değerlendirildi.

İstatistiksel değerlendirme Statistical Package for Social Sciences (SPSS) for Windows 20 (IBM SPSS Inc., Chicago, IL) programı kullanılarak yapıldı. Verilerin normal dağılımı Kolmogorov-Smirnov testi ile değerlendirildi. Sayısal değişkenler normal dağılım durumuna göre ortalama \pm standart sapma veya ortanca (en düşük değer- en yüksek değer) olarak gösterildi. Gruplar arası kıyaslamada normal dağılım gösteren sayısal değişkenlerde student $\mathrm{t}$ testi ve ANOVA testi, normal dağılım göstermeyen sayısal değişkenlerde Mann Whitney $U$ testi ve Kruskall Wallis $H$ testi ile değerlendirildi. Kategorik testlerin kıyaslanmasında Kikare testi, Fisher Exact test kullanıldı. Mortalite analizleri için Kaplan Meier analizi kullanıldı. İstatistiksel analizlerde $\mathrm{p}<0.05$ değeri anlamlı olarak kabul edildi.

\section{Bulgular}

Çalışmaya 239 hasta dahil edildi. 127 (\%53) hastanın hiç sigara içmediği, 69 (\%29) hastanın hemodiyaliz tedavisi ile beraber sigara kullanımını bıraktığı, 43 (\%18) hastanın ise aktif sigara içicisi olduğu tespit edildi. Hastaların demografik özellikleri Tablo 1'de özetlenmiştir.

Hastaların sigara içimi ile ilgili değerlendirmesinde eğitim düzeyi arttıkça, sigara içme oranının arttığ görüldü $(p<0,001, r=0,0466)$. Sigara içenler ve içmeyenler arasında hemodiyaliz sıklığı ya da damar erişim yolu arasında fark saptanmadı $\left(\mathrm{p}_{\text {sıklık }}=0,577\right.$, $\left.p_{\text {damar erişimi }}=0,363\right)$. Charlson komorbidite indeksine göre hastalar komorbiditeleri açısından değerlendirildiğinde hiç sigara içmeyen ya da sigara içip bırakmış hastalarda komobidite skorları benzerken aktif sigara içen hastalarda sigara hiç içmemiş ya da içip bırakmış hastalara göre daha düşük gözlendi $(\mathrm{p}<0,001)$. Sigara içip bırakan hastaların toplam sigara maruziyeti, aktif sigara içenlerden daha yüksek saptand, ancak istatistiksel fark gösterilemedi $(35 \pm 28$ paket/yıl vs $28 \pm 20$ paket/yıl, $\mathrm{p}=0,175)$. FNBT skorları değerlendirildiğinde; ortanca skor değeri 2 olarak saptand $1(\min =0, \max 9)$. Skor yüksekliği, erkek cinsiyet $(p=0,042, r=0,316)$, tüketilen sigara miktar1 $(p<0,001, r=0,643)$ ve evli olmak $(\mathrm{p}=0,031, \mathrm{r}=0,334)$ ile pozitif korelasyon gösterdi. Ölüm gerçekleşen hastalarda komorbidite skorunun daha yüksek olduğu görüldü ( $\mathrm{p}=0,001)$.

Hemodiyaliz tedavisine başladıktan sonra sigarayı bırakan hastaların ortalama sigara bırakma süresi $6,3 \pm$ 5,5 ay olarak hesaplandi. Hastalar diyaliz parametreleri açısından karşılaştırıldığında hemoglobin, albümin, kt/v, parathormon ve ferritin değerleri ile sigara kullanımı ya da FNBT skoru arasında ilişki gösterilemedi. Serebrovasküler olay geçirmiş hastalar $(p=0,011)$ ve damar erişim yolu olarak kalıcı tünelli kateter kullanan hastalarda $(p=0,002)$ İDİ daha düşük izlendi. İDİ düşük olan hastaların sigarayı daha erken bıraktığı gözlendi ( $\mathrm{p}=0,005)$.

Sigara grupları sağ kalım açısından karşılaştırıldığında, tüm gruplarda 3 y1llık takipte 41 hasta kaybedildi ve ortalama sağ kalım süresi $33 \pm 1$ ay saptandı. Aktif sigara içenlerde diğer gruplara göre sağ kalım daha uzun görüldü, ancak istatistiksel olarak fark saptanmadı. $(\mathrm{p}=0,054)$.

\section{Tartışma}

Sigara kullanımı dünya genelinde en önemli morbidite ve mortalite sebepleri arasındadır. Sigara bağımlılığının hem fizyolojik hem psikolojik komponentleri bulunmaktadır. Diyaliz hastalarında sigara bağımlılığı hastaların \%18'inin aktif olarak sigara kullandığ 
Tablo 1. Demografik Özellikler

\begin{tabular}{|c|c|c|c|c|c|}
\hline Parametre & $\begin{array}{c}\text { Hiç sigara } \\
\text { içmeyen }(n=127)\end{array}$ & $\begin{array}{c}\text { Sigara içip } \\
\text { bırakmış }(\mathrm{n}=69)\end{array}$ & $\begin{array}{c}\text { Aktif içici } \\
(\mathrm{n}=43)\end{array}$ & $\begin{array}{l}\text { Toplam } \\
(\mathrm{n}=239)\end{array}$ & $\mathbf{P}$ \\
\hline Yaş (yıl, ort \pm ss) & $63 \pm 12$ & $64 \pm 10$ & $51 \pm 9$ & $61 \pm 12$ & $<0,001$ \\
\hline Cinsiyet (n, K/E) & $86 / 41$ & $4 / 65$ & $6 / 37$ & $96 / 143$ & $<0,001$ \\
\hline $\begin{array}{l}\text { Medeni Durum } \\
\text { (n, Bekar/Evli) }\end{array}$ & $41 / 86$ & $13 / 55$ & $9 / 34$ & $63 / 175$ & 0,092 \\
\hline $\begin{array}{l}\text { Diyabetes Mellitus } \\
(\mathrm{n},-/+)\end{array}$ & $76 / 51$ & $49 / 20$ & $33 / 10$ & $158 / 81$ & 0,077 \\
\hline Hipertansiyon (n, -/+) & $56 / 71$ & $34 / 35$ & $19 / 24$ & $109 / 130$ & 0,769 \\
\hline $\begin{array}{l}\text { Serebrovasküler olay } \\
(\mathbf{n},-/+)\end{array}$ & $117 / 10$ & $69 / 0$ & $43 / 0$ & $229 / 10$ & $<0,001$ \\
\hline Koroner Arter Hastalığı $(\mathbf{n},-/+)$ & $84 / 43$ & $61 / 8$ & $39 / 4$ & $184 / 55$ & $<0,001$ \\
\hline KOAH (n, -/+) & $111 / 16$ & $61 / 8$ & $42 / 1$ & $214 / 25$ & 0,153 \\
\hline Komorbidite skoru (ort \pm ss) & $5,02 \pm 1,8$ & $5,1 \pm 1,4$ & $3,7 \pm 1,6$ & & \\
\hline Ölüm (n, -/+) & $98 / 29$ & $61 / 8$ & $39 / 4$ & $198 / 41$ & 0,054 \\
\hline
\end{tabular}

hakkında yeterli veri bulunmamaktadır. Çalışmada, \%29'unun sigara içip bıraktığı, \%53'ünün ise hiç sigara kullanmadığı görüldü. Hemodiyaliz hastalarında sigara bağımlılığı düzeyi düşük izlendi. Aktif sigara içiminin erkeklerde, evli ve eğitim düzeyi yüksek olan hastalarda daha sık olduğu, sigara içimi ile diyaliz parametreleri arasında ilişki olmadığı, sigara içenlerde komorbidite skorunun daha düşük olduğu, hipertansiyon, serebrovasküler olay, akciğer hastalığ 1 ya da koroner arter hastalığı sıklığının daha az olduğu gözlendi. Hastaların 3 y1llik takibinde mortalite oranı \%17,1 saptandı ve sigara kullanımı ile hasta sağ kalımı arasında ilişki saptanmadi.

Hemodiyaliz hastalarında yaşam kalitesinin değerlendirildiği bir çalışmada sigara içme oranı \%17 civarındadır $[9,10]$. Sigara içme oranları hemodiyaliz hastalarında genel popülasyona göre düşük olmakla birlikte halen yüksek orandadır. Genel popülasyona göre düşük olması, hastaların kronik böbrek yetmezliği tanısı aldıktan sonra sigarayı bırakmaları konusunda teşvik edilmelerinden kaynaklı olabilir, çünkü hekim takibinde olan hastalara sigara içmenin böbrek yetmezliğini şiddetlendireceği, kalp hastalıklarını ve buna bağlı ölümü arttıracağı anlatılmaktadır. Yapılan çalışmalarda prediyaliz dönemdeki hastalarda sigara içmenin kardiyovasküler olay sıklığını 1,11-1,21 kat; diyaliz hastalarında ise yeni başlayan kalp yetmezliği riskini 1,58 kat, periferik arter hastalığını ise 1,68 kat arttırdı $\breve{g}_{1}$ gösterilmiştir [11]. Ayrıca diyaliz hastalarında sigara içmenin kardiyovasküler hastalık gelişimi için yaş, böbrek hastalığı etyolojisi, ırk, cinsiyet ve diabetes mellitus varlığından bağımsız bir risk faktörü olduğu da bilinmektedir [12, 13].
Sigara içme alışkanlığ 1 , dünya genelinde erkeklerde kadınlardan daha fazladır [14,15]. Bizim çalışma popülasyonumuzda dünya genelinden farklı olarak evli ve eğitim düzeyi yüksek hastalarda sigara içme oranı daha yüksek saptandi. Asya ve Avrupa'da yapılmış çalışmalarda bekar veya eğitim düzeyi düşük olan kişilerde sigara içme oranı ve bağımlılık oranı daha yüksek saptanmıştır $[16,17]$. Hemodiyaliz hastalarında ortaya çıkan bu farklılık; sigara içmenin getirdiği psikolojik bağımlılık ve beraberinde hemodiyaliz tedavisinin kişide yarattığı anksiyete ve depresyon eğilimi kaynaklı olabilir [18]

Çalışmaya dahil edilen hastalarda beklenenin aksine, sigara içenlerde serebrovasküler olay, $\mathrm{KOAH}$, koroner arter hastalığ sıklığ 1 ve komorbidite skoru ile ölüm oranı daha düşük saptandı. Bazı çalışmalarda sigara içme ile morbidite ya da mortalite arasında ilişki gösterilememektedir [19]. Bizim çalışmamızla, sigara içenlerin yaş ortalamasının daha genç olduğu, yaş ve eşlik eden hastalıklar nedeniyle komorbidite skorunun daha düşük olduğu, aktif içicilerde tüketilen sigara miktarının daha az olduğu ve belki bu nedenle sigaraya bağlı hasarın henüz ortaya çıkmadığı düşünülebilir.

Çalışmanın kısıtlılıkları olarak FNBT testi kullanılması ve izlem süresinin kısalığ 1 bulunmaktadır. FBNT, ülkemizde de geçerliliği saptanmış, dünya genelinde sigara bağımlılığını ölçen bir testtir, ancak Fagerstrom testlerinde asıl amaç fiziksel bağımlılığın ölçülmesidir ve sigara içme dürtüsü, yoksunluk belirtileri, dikkatini yoğunlaştıramama ve davranış değişiklikleri gibi bağımlılığın diğer ölçütleri değerlendirilememektedir $[7,20]$. İzlem süresinin k1salığ 
çıkan koroner arter hastalığı ya da periferik arter hastalığı hakkında veri elde edilememiştir.

\section{Sonuç}

Sonuç olarak hemodiyaliz hastalarının yaşam kalitesinin artırılmasında tedaviye uyumlarının sağlanması ve sağlıklı yaşam biçimi davranıșlarının kazandırılması önemlidir. Bireylere olumlu sağlık davranışı kazandırmak için, bireyin bir davranışı yapıp yapmadığı ve etkileyen faktörlerin tanınması gerekmektedir. Hemodiyaliz ilișkili parametrelerin sigara bırakmaya ve bağımlılığa etkili olmaması, bu hasta grubunda sosyal destek ve eğitimle daha kolay sigara birakma sağlanabileceğini düşündürmektedir.

Sigara kullanımının hemodiyaliz hasta grubundaki etkilerinin gösterilmesi için daha çok hastanın yer aldığ uzun süreli araştırmalara ihtiyaç duyulmaktadır.

\section{Referanslar}

1.Mensah, GA, Wei, GS, Sorlie, PD, Fine, LJ, Rosenberg, Y, Kaufmann, PG, et al. Decline in Cardiovascular Mortality: Possible Causes and Implications, Circulation Research, 2017, 20, 120(2) 366-380.

2. Dube, SR, Asman, K, Malarcher, A, Carabollo R: Cigarette smoking among adults and trends in smoking cessation-United States, 2008. MMWR Morb Mortal Wkly Rep 2009, 58, 1227-1232.

3. Robinson, BM, Zhang, J, Morgenstern, H, Bradbury, BD, Ng, LJ, McCullough, KP et al, Worldwide, mortality risk is high soon after initiation of hemodialysis, Kidney International, 2014, 85(1), 158-65.

4. Süleymanlar, G, Ateş, K, Seyahi, N, Türkiye 2017 Yılı Ulusal Nefroloji, Diyaliz ve Transplantasyon Kayıt Sistemi Raporu

5.Li, N, Thadhani, RI, Reviriego-Mendoza, M, Larkin, JW, Maddux FW, Ofsthun, NJ, Association of Smoking Status With Mortality and Hospitalization in Hemodialysis Patients, American Jounal of Kidney Disease, 2018, 72(5), 673-681. doi: 10.1053/j.ajkd.2018.04.004

6. Charlson, ME, Pompei, P, Ales, KL, MacKenzie, CR, A new method of classifying prognostic comorbidity in longitudinal studies development and validation, Journal of Chronic Disease, 1987 40(5), 373-83.

7. Uysal, MA, Kadakal, F, Karșida ğ, C, Bayram, NG, Uysal, O, Yılmaz, $\mathrm{V}$, Fagerström test for nicotine dependence: reliability in a Turkish sample and factor analysis, Tuberkuloz ve Toraks, 2004, 52, 115-121.

8. Hong, WP, Lee, YJ, The association of dialysis adequacy, body mass index, and mortality among hemodialysis patients, BMC Nephrology, 2019, 22, 20(1), 382, doi: 10.1186/s12882-019-1570-0.

9. Başarır, S, Çınar Pakyüz S, Hemodiyaliz Hastalarının Sağlıklı Yaşam Biçimi Davranışlarının Değerlendirilmesi, Nefroloji Hem Derneği 2015, 10(1), 19-31.

10. Acartürk, G, Kazancıoğlu, R, Memişoğlu, E, Tepe, S, Çalışkan, Y, Türkmen, A et al. Renal Replasman Tedavisi Gören Hastalarda Koroner Arter Kalsifikasyonu, İstanbul Tip Fakültesi Dergisi, 2011 $70(1), 1-5$.

11. Orth, SR, Hallan, SI. Smoking: a risk factor for progression of chronic kidney disease and for cardiovascular morbidity and mortality in renal patients-absence of evidence or evidence of absence? Clinical journal of the American Society of Nephrology 2008, 3, 226-236.

12. Muntner, P, He, J, Astor, BC, Folsom, AR, Coresh, J, Traditional and nontraditional risk factors predict coronary heart disease in chronic kidney disease: results from the atherosclerosis risk in communities study, Journal of the American Society of Nephrology, 2005, 16, 529 538

13. Foley, RN, Herzog, CA, Collins, AJ, Smoking and cardiovascular outcomes in dialysis patients: The United States Renal Data System Wave 2 study, Kidney International, 2003, 63, 1462-1467.

14. Harrington, KM, Nguyen, XT, Song, RJ, Hannagan, K, Quaden, R, Gagnon, DR et al, A Million Veteran Program. Gender Differences in Demographic and Health Characteristics of the Million Veteran Program Cohort, Womens Health Issues, 2019, 25, 29
15. Yang, X, Jing, W, Gao, C, Attané, I, Smoking behavior of "marriage squeezed" men and its impact on their quality of life: A survey study in China, American Journal of Mens Health, 2019,13(3).

16. Jee, Y, Cho, Y, Health behaviors and health status of Korean middleaged men by marital status: Korea Community Health Study, 2015. Epidemiol Health, 2019, 41, e2019019.

17. Pennanen, M, Broms, U, Korhonen, T, Haukkala, A, Partonen, T, Tuulio-Henriksson, A et al. Smoking, nicotine dependence and nicotine intake by socio-economic status and marital status. Addictive Behaviour, 2014, 39(7), 1145-51.

18. Kocaman Yıldırım, N, Okanlı, A, Yılmaz Karabulutlu, E, Karahısar F, Özkan, S, Hemodiyaliz hastalarının anksiyete ve depresyon belirtilerine hastalık algısının etkisi: Cok merkezli bir çalıșma Anatolian Journal of Psychiatry, 2013,14:252-9.

19. Kiss, I, Kiss, Z, Kerkovits, L, Paksy, A, Ambrus, C. Smoking has no impact on survival and it is not associated with ACE gene I/D polymorphism in hemodialysis patients, Journal of Renin Angiotensin Aldosterone System, 2017, 18(1).

20. Berlin, I, Singleton, EG, Heishman, SJ, A Comparison of the Fagerström Test for Cigarette Dependence and Cigarette Dependence Scale in a Treatment-Seeking Sample of Pregnant Smokers, Nicotine \& Tobacco Research, 2016, 18(4), 477-83

http://edergi.cbu.edu.tr/ojs/index.php/cbusbed isimli yazarın CBU-SBED başlıklı eseri bu Creative Commons Alıntı-Gayriticari4.0 Uluslararası Lisansı ile lisanslanmıștır.

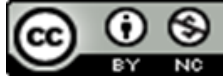

